\title{
Response to Commentaries
}

\author{
Hayne W. Reese \\ West Virginia University
}

The four commentaries on my essay about the relationship of physiology to behavior analysis (Reese, 1996) agreed that behavior analysis is an independent science and agreed with Skinner's (e.g., 1974, p. 215) point that physiology might someday broaden the scope or deepen the understanding of behavioral phenomena. Baer (1996) implied that physiology is not the only discipline that might eventually have these effects; and Bullock (1996) and Donahoe (1996) showed that progress has in fact been made in the simulation of neural mechanisms related to classical and operant conditioning. Poling and Byrne (1996) said that although they were not sure how physiological products differ from physiological processes, they were sure that taking the products into account would not advance behavior analysis.

That point excepted, I found the commentaries informative and helpful for further clarification of the relations between physiology and behavior analysis. However, I would like to expand upon some of the statements and to quarrel with some others.

\section{Is Behavior Analysis a Branch of Biology?}

Donahoe quoted part of a dictionary definition of biology ("a science that deals with living beings and life processes") and argued that because behavior occurs only in living beings and behavior analysis deals with behavior, behavior analysis is a branch of biology. I disagree with the argument, for reasons discussed in the next two paragraphs, but I also think that the valid-

Address correspondence to the author at the Department of Psychology, West Virginia University, P.O. Box 6040, Morgantown, West Virginia 26506-6040. ity of this part of his argument is not relevant to the validity of the rest of his argument, which is about the usefulness of identifying physiological mechanisms that underlie behavior and behavioral mechanisms.

The definition of biology quoted by Donahoe is slightly but not importantly different from the one in Webster's Third (1976), but the latter definition continues with the phrase "including zoology, botany, morphology, genetics, embryology, and allied sciences" (p. 218). The meaning of allied sciences is not specified, but the definitions of $z o$ ology (p. 2661), botany (p. 258), morphology (p. 1471), genetics (p. 946), embryology (p. 740), and physiology (p. 1707) include the phrase "branch of biology." Behavior analysis is not defined in Webster's Third, but the definitions of behaviorism (p. 199), "behavior psychology" (p. 199), and psychology (p. 1833) do not refer to biology at all. Furthermore, psychology is defined in two ways: "the science of mind or of mental phenomena and activities" and "the science of behavior." Behavior analysis is evidently a branch of the latter kind of psychology.

Of course, arguments based on dictionary definitions are not definitive. However, my argument is supportedalthough obviously not proved-by the departmental affiliations of a sample of behavior analysts. I tallied the addresses of the approximately 150 full, supporting, and sustaining members of the Association for Behavior Analysis whose names started with $A$ or $B$ in the 1994 membership directory and found that about half gave only street addresses. The others gave institutional addresses, and about half were in departments of psychology, one was in a Physiology and Behavior unit, none was in a department of biology, and 
none was in a neuroscience department. Based on the commonality of subject matter, indicated in the preceding paragraph, and the predominant departmental affiliation, behavior analysis is evidently a branch of psychology rather than biology. Therefore, behavior analysis is probably much more likely to have a significant influence on psychology than on physiology or neuroscience. A further implication, based on Poling and Byrne's argument that behavior analysts should not gratuitously offend their allies, is that behavior analysts should downplay opposition to psychology.

\section{Roles of Physiological Products}

I rather liked my exemplary experiment, but I had thought that evidence such as Poling and Byrne cited in criticizing it came from group research. I would appreciate having the references for relevant behavior-analytic studies.

I agree with Francis Bacon that "if anyone conceive that my forms are of a somewhat abstract nature, because they mix and combine things heterogeneous ...., he may be assured that his mind is held in captivity by custom, by the gross appearance of things, and by men's opinions. For it is most certain that these things, however heterogeneous and alien from each other, agree in the form or law which governs [them]" (Bacon, 1620/1960, Book 2, Aphorism XVII, p. 153). In science, "we are not to imagine or suppose, but to discover, what nature does or may be made to do" (Book 2, Aphorism X, p. 130), although we need not eschew testable hypotheses (Book 2, Aphorism XIV, pp. 150-151).

If my hypotheses are correct, the products of physiological processes are superficially heterogeneous but fall into a small set of stimulus classes. The stimuli in a class have a property in common (e.g., Malott, Whaley, \& Malott, 1993, p. 213; Skinner, 1938, pp. 34-35), but I believe Skinner (1938) misspoke in saying that "the defining property of the stimulus [class] is iden- tified as the part common to the different stimuli found to be effective" (p. 35). A stimulus class is actually defined not by a common physical property but by a common effect, that is, a common function (e.g., Kantor, 1933; Sidman \& Tailby, 1982).

\section{What the Physiologist of the Future Will Tell Us}

Skinner said, "The physiologist of the future will tell us all that can be known about what is happening inside the behaving organism. His account will be an important advance over a behavioral analysis, because the latter is necessarily 'historical'-that is to say, it is confined to functional relations showing temporal gaps. ... What he discovers cannot invalidate the laws of a science of behavior, but it will make the picture of human action more nearly complete" (1974, p. 215). Poling and Byrne quoted the part before the suspension points, and Donahoe quoted all but "What he discovers cannot invalidate the laws of a science of behavior," which is the point that Baer emphasized. Poling and Byrne and Donahoe interpreted the statement to mean that Skinner acknowledged the relevance of physiology to behavior analysis, but I think he meant that physiology potentially can supplement behavior analysis because physiology deals with a domain-what is happening inside the organism-that behavior analysis does not deal with. Comments by Baer are consistent with my interpretation.

In the paragraph preceding the one from which the above quotation was taken, Skinner rejected the idea that freedom from war, crime, and economic cycles will come about when the human brain increases in size (he was responding to a statement he had just quoted). He said, "There could scarcely be a better example of the damaging effect of the inner-directedness of physiological, as well as mentalistic, inquiry. If we are to be free from war, crimes, and economic booms and de- 
pressions, we shall have to find a better social environment" (1974, p. 214). Further, he said at the end of his discussion of the conceptual nervous system, "like the study of consciousness and the real nervous system, a model or system continues to turn attention inward, away from a genetic and personal history" (p. 218, emphasis added). The same view is expressed in Baer's commentary: Knowledge about physiological mechanisms may someday supplement knowledge about behavioral mechanisms, but physiological explanations cannot replace behavior-analytic ones.

\section{The Independence of Sciences}

All four commentaries agreed that behavior analysis can be an independent science, and although Bullock and Donahoe argued that a synthesis with physiology is desirable, I agree with Baer that behavior analysis will be fully sufficient if it continues its independence. I also agree with a further point implied by Baer in his reference to "the next discipline" that might someday contribute to the understanding of human action: Although all four commentaries mentioned potential or actual contributions from biological sciences, biology is not the only discipline that might someday supplement behavior analysis. Bullock and Poling and Byrne also agreed. Bullock mentioned cognitive psychology, social psychology, psychophysics, and ethology, and Poling and Byrne mentioned pharmacology, cultural anthropology, and economics.

However, the "grand synthesis" envisioned by Bullock seems to me (and to Baer and Poling and Byrne) not "well under way" but in an initial phase. The work Bullock cited on classical conditioning is directly relevant to only a small part of behavior analysis, and the work Donahoe cited on stimulus-stimulus relations at the neural level may be relevant to only a structural explanation of the formation of equivalence classes. A basic tenet of behavior analysis is that complex behaviors are built of simpler ones, but the relevance of the simple behavioral processes discussed by Bullock and by Donahoe to complex processes is conjectured rather than experimentally demonstrated and seems to be a long way from explaining, for example, Horne and Lowe's (1993) findings on interactions between rule governance and contingency shaping. Bullock and Donahoe take demonstration by simulation to be a useful step, but they also recognize the need for experimental analysis (as shown by Bullock's remark about a neural model that "awaits experimental test" and the paper by Donahoe, Burgos, \& Palmer, 1993).

\section{REFERENCES}

Bacon, F. (1960). The new organon. In F. H. Anderson (Ed.), The new organon and related writings (pp. 31-268). Indianapolis, IN: Bobbs-Merrill. (Reprint of J. Spedding, R. L. Ellis, \& D. D. Heath, 1863, translation; original work printed 1620)

Baer, D. M. (1996). On the invulnerability of behavior-analytic theory to biological research. The Behavior Analyst, 19, 83-84.

Bullock, D. (1996). Toward a reconstructive understanding of behavior: A response to Reese. The Behavior Analyst, 19, 75-78.

Donahoe, J. W. (1996). On the relation between behavior analysis and biology. The Behavior Analyst, 19, 71-73.

Donahoe, J. W., Burgos, J. E., \& Palmer, D. C. (1993). A selectionist approach to reinforcement. Journal of the Experimental Analysis of Behavior, 60, 17-40.

Horne, P. J., \& Lowe, C. F. (1993). Determinants of human performance on concurrent schedules. Journal of the Experimental Analysis of Behavior, 59, 29-60.

Kantor, J. R. (1933). In defense of stimulus-response psychology. Psychological Review, 40, 324-336.

Malott, R. W., Whaley, D. L., \& Malott, M. E. (1993). Elementary principles of behavior (2nd ed.). Englewood Cliffs, NJ: Prentice Hall.

Poling, A., \& Byrne, T. (1996). Reactions to Reese: Lord, let us laud and lament. The Behavior Analyst, 19, 79-82.

Reese, H. W. (1996). How is physiology relevant to behavior analysis? The Behavior Analyst, 19, 61-70.

Sidman, M., \& Tailby, W. (1982). Conditional discrimination vs. matching to sample: An expansion of the testing paradigm. Journal of 
the Experimental Analysis of Behavior, 37, 5- Skinner, B. F. (1974). About behaviorism. New 22.

York: Knopf.

Skinner, B. F. (1938). The behavior of organWebster's third new international dictionary of isms: An experimental analysis. New York: Appleton-Century-Crofts. the English language unabridged. (1976). Springfield, MA: Merriam. 